\title{
SUBJETIVIDADE CONTEMPORÂNEA, DISPOSITIVOS MÓVEIS E AFETOS
}

\author{
Ieda Tucherman ${ }^{1}$
}

Resumo: Neste texto propomos pensar a relação entre a subjetividade contemporânea e as tecnologias digitais, especialmente os telefones celulares e alguns de seus aplicativos, sobretudo os ligados às funções da imagem. Genealogicamente recuperam, em tempo real, antigas práticas tais como os filmes familiares dos irmãos Lumière e os diários de viagem, ao mesmo tempo em que modificam as lógicas de afetos e vínculos. Isto implica em pensar no estatuto atual da experiência, hoje midiatizada, na mudança da pergunta ontológica do Quem para o Onde você está, assim como compreender o surgimento e a prática de um novo mercado de produção e consumo de imagens.

Palavras- chave: Subjetividade, telefones celulares, imagens, afeto e consumo.

Abstract: In this text we propose to think about the relationship between contemporary subjectivity and digital technologies, especially cellular phones and some of their apps, especially those related to the functions of the image. Genealogically they recover, in real time, old practices such as the family films of the brothers Lumière and the journals of travel,and, at the same time that modify the logics of affections and bonds. This implies thinking about the status of today's mediated experience in changing the ontological question of Who to Where you are, as well as understanding the emergence and practice of a new market for the production and consumption of images.

Keywords: Subjectivity, cell phones, image, affections, consumption.

\section{Introdução}

\section{“Eu sou na medida das minhas conexões” Roy Ascot}

Como este texto decorre de uma conversa realizada com um grupo de pesquisa vou me permitir manter o tom coloquial. Que, aliás, me parece bem coerente com o objeto que escolhi para analisar. $\mathrm{O}$ eu, pequeno nome próprio, na acepção de Nietzsche, aí deriva do tom do texto e não de um narcisismo intelectual. Enquanto subjetividade contemporânea e afetos tem sido meu campo de estudo, as tecnologias atuais tem comparecido na minha pesquisa em função da sua influência no texto, no contexto e no efeito que produzem neste conturbado campo das afecções e dos sentimentos na nossa atualidade.

Por terem uma presença mais constante e distribuída e terem gerado protocolos que conformam nosso comportamento, minha escolha, entre as tecnologias móveis possíveis,

\footnotetext{
${ }^{1}$ Doutora em Comunicação e Cultura pela Escola de Comunicação da Universidade Federal do Rio de Janeiro com pós-doutorado no IRCAM, Centro Georges Pompidou, Paris. Professora e Pesquisadora do Programa de Pós-Graduação e Pesquisa da UFRJ, onde coordena um grupo de pesquisa, Imaginário Tecnológico. Bolsista de pesquisa do CNPq.
} 
recaiu sobre os telefones celulares e seus aplicativos e duas observações são obrigatórias: há uma espécie de comando: "não saia de casa sem ele”, e uma constatação: o que é menos usado é a função telefonia, por este motivo, e eu gostaria de explorar nele a presença e o uso das imagens.

Para compreender esta torção e seguir o vício genealógico de quem tem as heranças de Nietzsche e Foucault como referências, pensei propor, neste primeiro arranjo, uma leitura genealógica que tornasse visível a relação entre práticas e experiências antigas e os novos usos do celular e de seus aplicativos. Isto traz a cena quatro eixos, ou seja, situações onde relacionar os celulares a partir dos aplicativos ligados à geração e transmissão de imagens parecem, se não retomar, ancorar-se numa experiência anterior:

1- Retomam os filmes familiares do nascimento do cinema, como os dos irmãos Lumière.

2- Retomam os diários de viagem- em tempo real

3- Modificam a lógica subjetiva de amores e amizades: de vínculos passam a conexões.

4- Como em toda Internet o problema é excesso- o que se esconde, de certa maneira, pela ideia de compartilhamento.

Pensar a subjetividade contemporânea aponta para uma questão que se torna urgente: qual o estatuto atual da experiência? Se a nossa preocupação incluir o aspecto ético ou, mesmo remotamente, passar pela questão foucaultiana de uma estética da existência, a pergunta terá um complemento: Quais são as experiências desejáveis? Quais são aquelas que operam a favor da liberdade?

Tradicionalmente experimentar se opunha a contemplar ou deduzir. Pensando no conceito de dispositivo, proposto por Foucault e retomado por Agamben, que o define como um conjunto heterogêneo de linhas de saber, poder e subjetividade que atrai instituições, comportamentos, discursos, dispondo de uma historicidade externa, a saber, entre os dispositivos anteriores e uma interna que é própria da dinâmica de tensão destas linhas, a questão é onde e como os celulares se encaixam na pergunta sobre o campo das experiências. Foucault não os conheceu, Agamben fala de dispositivos de desubjetivação. O que eu gostaria de fazer, sem maior pretensão do que o pensar em voz alta, segue no mesmo caminho. 
Para provocar, a desubjetivação é uma forma de subjetivação- em termos lógicos: o não ser uma coisa determinada pertence ao campo de possibilidades desta coisa, e assim podese propor que sua descentralidade, instabilidade, flexibilidade e conectividade seria parte de um processo que distingue a atualidade subjetiva da subjetividade moderna A última se caracterizava por ser centralizada, interiorizada, buscando afirmar-se a partir de dois lemas :autonomia e autenticidade. Hoje, em nossa atualidade subjetiva, teríamos identidades performáticas e subjetividades prêt-à-porter (Rolnik) que trocamos assim como mudamos de roupa. ,

É possível fazer uma analogia, usando ainda outra versão do conceito de dispositivo, o de Jean Louis Baudry ${ }^{2}$, que relacionou tecnologia, comportamento e ideologia, para pensarmos o celular com seus aplicativos. O campo do Baudry é o cinema e ele demonstra que o cinema que não é a sala ou o filme, mas o ritual, a sala escura, a luz que vem de trás demandando intenso uso do estímulo visual e um mínimo movimento motor, o que vai precisar inventar, no sentido radical do termo, um corpo novo. Não é por acaso que este corpo desconhecido vai levantar um problema que vai ocupar parte importante dos saberes da virada do século XIX para o século XX: o de um corpo moldado para um espectador, trazendo consigo a questão da atenção.

Vale lembrar que os filmes dos Lumière duravam três minutos. Um diretor propôs, no início do século XX, rodar um filme de meia hora e Edison, o dono do estúdio, chamou-o de maluco: quem iria suportar 30 minutos? Ele estava considerando o que $\mathrm{Crary}^{3}$ Hoje quando muito poucos filmes tem menos de duas horas e pouco, parece engraçado lembrar disto.

Nestes termos, o celular também propõe um corpo do qual é uma prótese- só que as próteses não são um algo que se encaixa e desencaixa segundo necessidades específicas, como um pé de pato, por exemplo; que parece caracterizar a relação entre a nossa atualidade a as tecnologias digitais é que estas são o ambiente e as novas condições da experiência.

Para Roger Odin, numa palestra informal na Escola de Comunicação da UFRJ, o celular substituiu a questão ontológica O que? Quem? Por uma pergunta Onde você está? Vale lembrar que o celular como dispositivo pertence ao que Deleuze chamou de sociedade de controle e tem aí função GPS. Só como plano futuro, comprimindo o tempo, os celulares tornaram visíveis as políticas de espaço, tanto as afetivas quanto as de vigilância.

\footnotetext{
2 Apud Jonathan Crary, Técnicas do Observador, 2012.

${ }^{3}$ Crary, J, Técnicas do Observador, Rio de Janeiro, Contraponto, 2014.
} 
Nesta perspectiva de subjetividade por exterioridade - reconhecimento pelo outro- nos tornamos visíveis nos selfies que, postados, acrescentam o que estamos nos tornando. Curiosamente na invenção da fotografia, já pensando em afetos para Benjamin, uma das tarefas da fotografia era captar o que ia desaparecendo. Ainda temos maravilhosas experiências travadas neste contexto: basta lembrar as fotos de Gordon Matta Clark registrando as obras para erguer o Centre Pompidou e as transformações em Les Halles.

Por outro lado, e isto é ligado à lógica dos dispositivos de visibilidade como produtores de imagens ou evidências (um exemplo seria o filme Falsely Accused- estúdio Edison $)^{4}$ parece que há aí uma influência das imagens médicas nas imagens culturais; se quisermos pensar numa imagem que torne esta relação explícita, basta pensar no quadro Lição de Anatomia do Dr. Kulp de Rembrandt de 1632, época que sabemos ter sido a da constituição da ciência médica. A ideia, por isto falamos da Anatomia, mas vale, a partir daí para os sofisticados exames de visibilidade, começando pelo que constrói a lógica desta linha: a radiografia, que faz aparecer o invisível, o interior do corpo, além de tudo fragmentado. Alguns críticos de arte já disseram, por exemplo, que Picasso deve mais à radiografia do que ao talento de Cézanne, considerado o pai da pintura da alta modernidade, a possibilidade do seu cubismo, um jogo de fragmentação desde o início,

O que reforçou o campo da medicina criou também um critério não totalmente desvelado: o de que a premissa de evidência é efetivamente mais do que a pura demonstração de presença já busca afirmar que esta é como o reduto profundo da verdade. ${ }^{5}$

Daí decorrem: os atuais filmes postados no Youtube ou no Whatsapp, que, quando dirigidos aos mais "íntimos" ou quando "festejam as tecnologias visuais "mostram" o que ainda não é: um exemplo familiar é o da minha sobrinha que posta todo mês as ultrassonografias em 3D da Júlia- que vai nascer no fim de agosto, mas cujo nariz é da família do pai. Como estou escrevendo em setembro, deu tudo certo, e ela é uma gracinha, realmente parecida com seu pai. Mas imaginemos que tivesse havido um problema e tivéssemos perdido a Júlia (cujo nome foi escolhido desde que se soube que era uma menina, com três meses de gravidez); não seria um luto muito mais duro, pois nós conhecíamos a figurinha?

\footnotetext{
${ }^{4}$ TOM Gunning, O retrato do corpo humano: a fotografia, os detetives e os primórdios do cinema, in O Cinema e a invenção da vida moderna, 2001.

${ }^{5}$ Para quem vê os seriados médicos televisivos são muitos os exemplos; o mais expressivo é o do House que afirma que o paciente mente, mas os exames não.
} 
Isto me lembra o humor irônico de Baudrillard, nos anos 90 quando pensava nos simulacros e saiu-se com esta boutade: duas mães se encontram na pracinha onde levaram os filhotes para brincar e uma comenta com a outra: seu filho é lindo. A outra responde, feliz, é porque você não viu as fotos dele. Hoje como diz uma amiga que tem um filho pequeno- 1 dia sem fotos ou vídeo é um dia perdido. Parece que o afeto familiar é menos ligado ao "care" provido à criança e mais à atenção em documenta-la.

Remete aos filmes familiares-agora em tempo real- mas altera a postura da própria criança-ela vive para o registro e, exagerando, é a permanente atriz de um filme que os pais não editam. E cada cena tem que ser clicada, uploaded e enviada. Um texto que li há anos numa aula de francês e cuja referência perdi, escrito por um psicanalista, chamava-se Éloge de la Grimace, (Elogio da Careta) ou seja, elogio da careta e nele o autor dizia que a defesa da criança quando se vê exposta para aquelas perguntas constantes: parece com o pai ou com a mãe? É fazer uma careta: assim ela recupera a posse do próprio rosto. Não me parece que hoje as crianças reajam mais à exposição neste sentido. Quando fazem caretas parece ser para ter um novo registro.

Por estranha que possa parecer tal analogia, Agamben num texto sobre pornografia ${ }^{6}$ fala que a diferença para as fotos das prostitutas que, no final do século XIX, início do XX eram vendidas primeiro nos bordéis depois nas estações de trem, bares além de outros redutos masculinos, para as fotos de outras mulheres que posavam para retratos era que estas olham sem timidez para a câmara enquanto nas outras fotos as pessoas parecem pouco à vontade. As crianças de hoje olham para a câmara com zero constrangimento.

O mesmo vale para as reuniões familiares, acontecimentos sociais e comemorações: a foto ou vídeo tem que ser feita em tempo real e divulgada. $\mathrm{O}$ curioso é que as pessoas passam a noite olhando os celulares, em vez de se olharem. Minha aposta é que há mais comemorações familiares e outras: tantos anos de formatura no colégio, na universidade, tantos anos de uma viagem e por aí vai mais para festa da técnica do que dos afetos. Aplicativos como o Facebook ajudam a encontrar e convocar as pessoas e a hipótese da documentação fotográfica é um incentivo. Eu me pergunto, mas é ruminação de paquiderme histórico, se há mesmo afeto entre estas pessoas. Certamente não é regra geral, mas dá para desconfiar se não é a exibição que conta, mais do que o próprio contato.

\footnotetext{
${ }^{6}$ Agamben, Pornographie in Nudités.
} 
Sem mencionar a hipertrofia, onde drones são contratados para fotografar casamentos e outros eventos e durante a festa ficam passando em telões as imagens que estão sendo feitas. Ficamos mais atentos ao filme da festa do que à própria. Sendo sinceros, pode ser um excelente recurso estético como o suposto vôo do 14 Bis que carregava um drone que ia filmando o Rio de Janeiro e projetando no Maracanã na abertura da Olimpíada, mas corresponde de certo modo àquela visão que costumamos ter numa mesa de bar ou restaurante: pessoas teclando e olhando para o celular, aparentemente sem registrar o que acontece presencialmente. Como dissemos antes, são condições novas de experiência. Mas a nós, o que importa tem a ver com afetos, e aí vemos com outras lentes. São afetos menos socializantes.

Afinal, isto significaria que, pela multiplicidade de imagens que produz conduz à demonstração do afeto familiar ou de ex-colegas? A mim parece que o afeto se desloca para o aparelho, sua performance tecnológica de mostrar todos os momentos. Quem sabe isto explique a viralização de vídeos de gatos e cachorros? As pessoas descobriram este amor ou a tecnologia os produziu?

Aliás, no campo dos afetos temos um dado muito interessante: os sites de relacionamento social ou de encontros atuam no sentido da flexibilização das relações. $\mathrm{O}$ lugar onde hoje faz sentido pensar em fidelidade é nas marcas publicitárias: amores infiéis mas “j'adore Dior".

\section{Diários de viagem}

Desde os naturalistas que viajavam com os descobridores ou com os colonizadores, a imagem do outro tornou-se uma forma de relação centro-periferia sob a forma de bibliotecaBruno Latour em A esperança de Pandora mostra que o primeiro desenho de um pássaro tropical tornou possível uma situação totalmente nova: o dito pássaro podia estar presente em todos os reinos da Europa, onde este pássaro- real- nunca voaria. Cientistas como Lineu desenhava as folhas que via, Debret desenhava os habitantes e assim outras figuras entraram no imaginário europeu, no que Latour chama de um diálogo entre a periferia e o centro.

A literatura usou e abusou deste recurso, tanto nos romances de viagem quanto em observações de grandes autores. Afinal, a modernidade abusou deste tema e de festejar sua vitória do espaço pela aceleração, o que gerava sua nova possibilidade. Podemos lembrar de 
Goethe falando do prazer do anonimato naquela que não é a "a sua casa". Mas era uma literatura de viagem que teve e ainda tem excelentes exemplos. O mais lindo exemplo que conheço é Cidades Invisíveis de Ítalo Calvino. Mesmo sem os desenhos o desconhecido do mundo, mesmo quando tão perto, torna-se aguçado objeto de atração.

Mais tarde, pulando períodos e experiências e associando-se â lógica militar, temos imagens do espaço e dos movimentos demandando investimentos para poder dar conta da aceleração produzida pelos meios de transporte- trens, tanques, aviões etc. A este respeito, as reflexões de Paul Virilio em Guerra e Cinema $^{7}$ são exemplares. Agora, com a massificação das formas de registro, pessoas comuns viajam com suas máquinas fotográficas, filmadoras etc. E geram a ocupação de um espaço a ser palmilhado num exercício competitivo de obtenção de imagens.

Assim, sendo um pouco corrosiva, podemos ter 10 minutos de japoneses em Florença, já que viajam em grandes grupos e fotografam tudo que lhes passa pela frente ou ao lado e podem fazer pensar que A Fontana de Trevi é menos italiana do que da turma japonesa. Tive esta experiência este ano: cheguei em Roma no dia em que tiraram os tapumes que escondiam o monumento em reforma. O dia desta entrega foi anunciado: era absolutamente impossível vê-la: tapumes humanos e suas máquinas e paus-de-selfie a escondiam totalmente.

Ainda neste contexto, os mais velhos viveram o pesadelo de ter que ver os slides das viagens dos amigos: só que os filmes tinham limite, o que obrigava aos documentaristas a escolherem sob o risco de ficarem sem material. No entanto, como se acumulava uma viagem inteira... criava-se uma ocasião. Era a ocasião de juntar os amigos para mostrar, o que depois de alguns minutos ficava bastante entediante.

Hoje, como antecipamos citando Odin, o importante é onde você está e aí algumas situações merecem atenção: se importante é a sua presença nos lugares os selfies e paus de selfie devem mesmo proliferar nos museus. Eles são a localização GPS. Como as pessoas ficam se fotografando em frente às obras de arte e enviando em seguida, tornam quase inacessíveis as obras-de-arte. Adoro quando os museus proíbem. Nada me convence que não estejamos criando imageticamente um mundo tão narcísico que tudo o que há, inclusive, o que de mais belo a natureza ou a cultura produziram, tende a ser apenas pano-de-fundo para a própria imagem,

\footnotetext{
${ }^{7}$ Virilio, Guerra e Cinema, 2005.
} 
Ao mesmo tempo, e acrescentando outra direção, esta importância de estar no lugar transforma todo mundo em repórter fotográfico em potencial. Os celulares são hoje os grandes fornecedores de imagens de acidentes, crimes, etc. De toda maneira a atitude é a mesma- mostrar que se estava no lugar no momento preciso, o estar lá sendo, para quem faz a foto, mais importante do que o que está na foto. O resultado é curioso, já que trabalha-se de graça para as empresas de notícia: os egos ficam inflados enquanto os repórteres fotográficos são despedidos.

Num texto que se pretende coloquial e já deu mostras disto, valem duas curiosidades, uma delicada e afetiva e uma meio mórbida, ambas verdadeiras:

a- Tenho uma amiga que é psicanalista mas aficionada por culinária e cada vez que produz ou come uma receita especial, fotografa e envia por WhatsApp. Quando ela viaja todos nós engordamos!

b- O caso conhecido de uma moça que estava se fotografando na Golden Gate numa série de selfies de ângulos diferentes e numa das fotos aparece um homem pulando da ponte. Nem por isto ela deixou de dar upload e enviar. Faz lembrar um filme maravilhoso onde um acaso fotográfico (um crime) é o argumento para o AntonioniBlow Up. Com uma enorme diferença ética e estética: no filme o crime só aparece na revelação e engendra uma trama onde morte e vida não são imagens per se.

\section{Self e as redes sociais}

Como no título, as redes são frequentadas por selfies (perfis, fotos, que se utilizam do photoshop, a plástica virtual) que não são o self interiorizado moderno, assim como, efetivamente, não são da lógica do amor ou da amizade- que supostamente atraem e sustentam a diferença entre sujeitos e é, segundo Badiou, ${ }^{8}$ a condição de verdade do amor.

Quando, no entanto, o objetivo são as redes de encontro ou de relacionamento social, acionadas no imediato pelos aplicativos dos celulares, impõe-se outra situação. Num questionário que se deve produzir para desenhar o próprio perfil, alguns valores entram em cena. Para produzir um perfil na rede social 2 coisas se colocam:

É um mercado:

\footnotetext{
${ }^{8}$ Para Badiou, o que mantém o amor é a diferença, a ideia de uma relação de 2 sujeitos.
} 
1- preciso agradar, portanto me descrever segundo o que eu acho que faz sucesso. Daí surge a primeira fonte de incertezas: não sei se vou ser escolhida, ou se vou ter poucos amigos no Facebook ou poucos likes no Istagram.

2-Como escolher na sociedade do capitalismo afetivo9 ${ }^{9}$ significa avaliar e calcular, devo escolher quem me agregue valor: no mínimo aumente a minha rede. Nunca posso estar seguro que minha escolha é a melhor- talvez outro alguém fosse mais proveitoso.

\section{Deleuze: a vida imita a empresa}

Ambas as circunstâncias produzem um resultado comum: uma certa anorexia de engajamentos que se contrapõe à questão moderna onde a autonomia tinha a escolha como seu lugar de afirmação, o que o romantismo de Romeu e Julieta de Shakespeare, passando pela Dama das Camélias de Dumas e por toda a produção de Jane Austen, apenas para dar alguns exemplos, não cansou de explorar. O homem moderno era o que podia prometer.

Há ainda um dado relevante para pensar as questões de subjetivação e este tem a ver com a construção dos corpos. Assim como se está fabricando crianças para serem vistas, os adolescentes, idade que costuma trazer insegurança (aqui entre 13 e 15 anos) são os mais adeptos do auto retrato- e entre eles, as meninas são mais numerosas. Como elas navegam "se sentindo num contínuo concurso de beleza “, tendo como ídolo Kim Kardashian, conhecida por não ter talento nenhum mas levar uma vida de princesa, visível nas redes e na Tv a cabo e, no Brasil, Gabriela Pugliese, que alcançou fama postando fotos de si mesma malhando no Istagram, ninguém está contente com a própria imagem. Uma cultura do narcisismo que produz narcisos desiludidos. .

Neste momento da vida de insegurança e na desilusão da própria imagem e como não receber likes numa publicação on line gera ansiedade e depressão, aumentou exponencialmente a frequência de adolescentes nas mesas de cirurgia plástica. Até os 16 anos nos EUA campeões no caso, o sucesso é dos implantes no queixo que ressaltam o perfil. Depois dos 18 passamos para implantes de silicone no peito e na bunda. Afinal é a pátria do empreendedorismo- e dos winners e loosers.O primeiro movimento de empreendedorismo é o próprio corpo .É como se, num mercado competitivo, cada parte do corpo fosse vista como atrator ou detrator do olhar do outro.

\footnotetext{
${ }^{9}$ Expressão cunhada por Eva Illouz em Amor em tempos de capitalismo.
} 
Impossível não falar dos nudes: podem ser e parecer inocentes, ou um código de relacionamento entre casais- caso da Jennifer Aniston, mas todo mundo sabe que existe vazamento na rede. Não dá para não falar de um par: exibicionismo e voyeurismo, e dos casos extremos- bullying, pedofilia, etc. Também não podemos pensar que estes foram inventados pelas redes e suas plataformas: mas a agilidade de divulgação facilitou muito a replicação destes comportamentos.

Vale lembrar que, além da concepção indicial, todo retrato tem uma parcela ficcionalportanto cria-se uma inversão: em vez do corpo gerar uma imagem é a imagem que gera o corpo que vai ser exposto ao escrutínio do olhar do outro. Talvez aqui, nos selfies, caiba a ideia de personagem - o que distingue um personagem não é que ele seja fictício, em oposição a uma pessoa real. O que marca um personagem é que ele é o que precisa de testemunho- existe quando olhado.

Assim, nas redes sociais, nos sites de relacionamento tipo Par Perfeito, E Harmony mas também nos sites de encontro tipo Tinder e congêneres o que parecemos encontrar são construções de personagens pensados- estamos nos repetindo- em função do que se imagina, agrade ao mercado. A esta realidade chamei de sociedade de mercado considerando que economia de mercado temos desde o mercantilismo.

Enfim, quem tem um smarphone só fica sozinho se for incompetente. Estamos falando do dispositivo- celular mais aplicativos- saúde, auto ajuda, agenda, dicionários, previsão de tempo, banco, turismo, GPS etc. :estudando panoramicamente o caso do

Whatsapp: plataforma para todo tipo de conversa que incorpora texto, som e imagem. Talvez seja o mais utilizado como aplicativo universal de compartilhamento já que produz um efeito de aceleração pragmática. É super eficiente mas também gera problemas: num caso amoroso o whatsapp diz a que horas a mensagem foi enviada e a que horas foi lida pelo outro. Assim 2 horas de espera equivalem a 2 semanas de afastamento e ajuda a medir o grau de interesse.

Neste caso, se havia um código careta "princesa" - só atenda depois do telefone tocar 3 vezes, só dê no terceiro encontro, etc, agora o código de sedução programada é: não responda imediatamente, demore um pouco para enviar fotos. Acho que podemos falar de uma passagem dos afetos mais pregnantes: da angústia como afeto moderno- cuja presença nas relações amorosas se dava via ciúmes e para escritores modernos como Proust e Machado de Assis, o que nutria o amor era o ciúme sendo o chamado futuro imperfeito, para uma nova 
lógica. É menos importante ser único do que ser prontamente atendido. O novo afeto crítico é a ansiedade. E seu alimento é a aceleração.

\section{Considerações finais}

Como diz uma amiga- "se ele te telefonou, já é uma declaração de amor". Podia ter usado WhatsApp.

Para fechar, uma meme engraçadinha da rede:

Um casal em que a mulher faz as exigências:

Idade Média: vá e prove seu amor por mim. Mate 5 dragões.

Anos 50: Prove seu amor por mim: peça minha mão em casamento e responda ao questionário do meu pai.

Atualmente: prove seu amor por mim: mude seu status no facebook.

Prefiro terminar de forma mais poética:

"Eu não sou eu nem sou Outro

Sou qualquer coisa de intermédio,

Pilar da ponte de tédio

Que vai de mim para o Outro" -

Mário de Sá Carneiro

\section{Referências}

Agamben, G. Nudités, Paris, Payot et Rivages, 2009.

Badiou, A. Eloge de l'amour, Paris, Flammarion, 2009.

Ehrenberg, A. La fatigue d'être soi, Paris, Odile Jacob, 2000.

Foucault, M. Nietzsche genealogia e história. In: Microfísica do Poder, Rio de Janeiro, Graal, 1989. 
Gunning, T. O retrato do corpo humano: a fotografia, os detetives e os primórdios do Cinema. In: O cinema e a invenção da vida moderna. Org Charney, L e Schwartz, V, São Paulo, Cosac \& Naify, 2005.

Illouz, E. O amor em tempos de capitalismo, Rio de Janeiro, Zahar, 2011.

Pourquoi l’amour fait mal?. Paris, Seuil 2012.

Latour, B. A esperança de Pandora, Bauru, Edusc, 2001.

. Políticas da natureza, Bauru, Edusc, 2004.

Tucherman, I. Fabricando corpos: ficção e tecnologia. Lisboa, Revista de Comunicação e Linguagens 33, 2004.

Turkle, S. Alone together, New York, Perseus Basic Books, 2011. 